\title{
A IDENTIDADE DA DISCIPLINA FILOSOFIA E DO DOCENTE NO CURRÍCULO DO ENSINO MÉDIO
}

\author{
Geraldo Adriano Emery Pereira* \\ Isabel Thereza de Holanda Freitas \\ João Vitor de Freitas Moreira \\ Patrícia Pontes Lopes
}

Resumo: O trabalho é um exercício de pensamento referente ao lugar da filosofia no currículo do ensino médio. A investigação considera a recente presença da filosofia como disciplina obrigatória em todas as séries da escola média brasileira. Assim, a condição curricular, e o próprio lugar do docente são ainda uma lacuna a ser preenchida. Para essa "atividade" as provocações de Hannah Arendt e de Gilles Deleuze figuram como o solo conceitual da reflexão.O exercício intelectual de Arendt sobre o "vazio de pensamento" e sua rigorosa análise sobre a faculdade de pensar articuladas com as provocações de Deleuze quanto a compreensão da filosofia como uma "produtora" e articuladora de conceitos, ditaram o caminho que sugere ser a filosofia, enquanto "disciplina", um parar para pensar como forma de contrapor o pensar ao fluxo laboral de consumo de conteúdos da escola média. Aqui a filosofia enquanto disciplina é uma contemplação tão ativa quanto a ação.

Palavras chave: ensino de filosofia, identidade, pensamento, educação.

Resumen: El artículo es un ejercicio de reflexión sobre el lugar de la filosofía en el plan de estudios de secundaria. La investigación considera la reciente presencia de la filosofía como asignatura obligatoria en todos los grados de la escuela media. Por lo tanto, la condición curricular y el propio lugar del maestro sigue siendo una brecha por cubrir. Por esta "actividad" las provocaciones intelectuales de Hannah Arendt y Gilles Deleuze se presentan como suelo conceptual de la reflexión. El ejercicio intelectual de Arendt sobre el "vacio de pensamiento" y su riguroso análisis de la facultad del pensar articulado con las provocaciones de Deleuze acerca de la comprensión de la filosofía como una "productora" y que articuladora de conceptos, dictaron la manera que sugiere ser la filosofia, en la condición de "disciplina", una pausa para pensar como una forma de contrarrestar el pensar al flujo laboral de consumo de contenidos de la escuela media. Aquí la filosofía como una asignatura es una contemplación tan activa como la acción. Palavras clave: enseñanza de la filosofia , identidad, pensamiento, educación.

O ensino de filosofia no Brasil tem uma história bastante complexa se considerarmos suas idas e vindas. É fato que para pensarmos a identi-

\footnotetext{
* Professor Efetivo de Filosofia do Colégio de Aplicação da Universidade Federal de Viçosa.O Texto é parte de uma pesquisa que ainda está em andamento. Na ocasião contou com o apoio do CNPQ na concessão de bolsas de iniciação científica júnior para PATRÍCIA PONTES LOPES, ISABEL THERESA DE HOLANDA FREITAS e JOAO VITOR DE FREITAS MOREIRA (na época alunos do ensino médio do Colégio de Aplicação da Universidade Federal de Viçosa- Minas Gerais - Brasil).. E-mail: geraldo.emery@ufv.br/ geralemery@hotmail.com
}

PEREIRA, Geraldo Adriano Emery et al. A identidade da disciplina Filosofia e do docente no currículo do Ensino Médio. Revista Sul-Americana de Filosofia e Educação. Número 21: nov/2013-abr/2014, p. 3-16. 
dade da disciplina Filosofia no contexto atual do currículo do ensino médio é necessário partirmos do pressuposto de que seu processo de identidade enquanto disciplina é para os filósofos que ensinam filosofia um problema fundamental.

Se partíssemos da indagação socrática do "conhece-te a ti mesmo" veríamos que esse adágio filosófico se aplica à atual condição existencial da filosofia enquanto disciplina; pois é necessário que a filosofia se autoreconheça ou reveja a sua identidade no intuito de questionar as condições de sua inserção no currículo do ensino médio.

No âmbito do currículo, as disciplinas representam um aparato de conteúdo, com finalidades específicas. No caso brasileiro as disciplinas são orientadas e organizadas sob a justificativa de possibilitarem aos alunos o desenvolvimento de um conjunto de habilidades e competências. Para o Ensino Médio, seriam habilidades e competências que segundo a LDB teriam como horizonte a habilitação para a vida do trabalho, bem como para a continuidade nos estudos a nível de graduação, seja ela tecnológica, bacharelado ou Licenciatura.

Art. 35. O ensino médio, etapa final da educação básica, com duração mínima de três anos, terá como finalidades:

I - a consolidação e o aprofundamento dos conhecimentos adquiridos no ensino fundamental, possibilitando o prosseguimento de estudos;

II - a preparação básica para o trabalho e a cidadania do educando, para continuar aprendendo, de modo a ser capaz de se adaptar com flexibilidade a novas condições de ocupação ou aperfeiçoamento posteriores;

III - o aprimoramento do educando como pessoa humana, incluindo a formação ética e o desenvolvimento da autonomia intelectual e do pensamento crítico;

IV - a compreensão dos fundamentos científico-tecnológicos dos processos produtivos, relacionando a teoria com a prática, no ensino de cada disciplina.

Quando visualizamos no currículo do Ensino Médio a presença obrigatória da filosofia - art.36,IV da Lei 9394/96 LDB - vemos a sua institucionalização como disciplina $e$ a conseqüente exigência de habilidades e competências próprias das disciplinas que compõem a base curricular da escola média.

Ao considerarmos a exigência de habilidades, competências e conteúdos a serem trabalhados em sala de aula, do ponto de vista da radicalidade da atividade filosófica, fica estabelecido um problema: as disciplinas apresentadas numa grade curricular trazem consigo o pressuposto da ensinabilidade, no caso da filosofia, se considerarmos a sua natureza plural, cabe por a questão: qual é o parâmetro de ensinabilidade da filosofia considerando a sua identidade $e$ o rol de habilidades e competências que a legislação brasileira aponta para a grade curricular da Escola Média?

Responder ou enfrentar com rigor e radicalidade essa questão é condição necessária para se posicioNúmero 21: novembro/2013 - abril/2014 
nar de uma forma razoável quanto a condição institucional de disciplina que atualmente reveste a filosofia.

\section{A problemática identidade da filosofia como disciplina}

Ao ler um filósofo contemporâneo ou até mesmo moderno é possível perceber que a todo instante o exercício de seu pensamento passa por um diálogo com seus predecessores ou contemporâneos, revisitando uma constelação conceitual. O diálogo mesmo que seja o de si consigo mesmo é uma marca da atividade filosófica. De modo que,

A história da filosofia não implica somente que se avalie a novidade histórica dos conceitos criados por um filósofo, mas a potência de seu devir quando eles passam uns pelos outros. (DELEUZE, 1992, p.46)

O desafio que nos propomos de abordar a identidade da filosofia como disciplina no ensino médio talvez possa passar por uma reflexão referente à característica que sem a qual a atividade filosófica não seria o que é, qual seja, o peculiar modo de exercitar o pensamento.

Hannah Arendt ao enfrentar o desafio de refletir sobre o pensar o faz sugerindo que ele se trata de uma atividade que implica um parar para pensar. O âmbito no qual ela aborda essa compreensão é o da definição platônica de que o pensar é um diálogo de si consigo mesmo, que requer a presença de si a si. Relacionar-se com as aparências numa complexa relação de presença e distância marcam o tom da reflexão que ela sugere.

Entretanto, o que nos interessa nesse breve ensaio é provocar o professor filósofo a especular: em que medida a filosofia em sala de aula, como disciplina, implica ou comporta a prática dialogal que lhe é própria? Seria um diálogo preso a um solipsismo da presença de si a si ou necessariamente exigente de um alteridade fundamental?

Hannah Arendt inicia o texto sobre o pensar apresentando uma perplexidade que a moveu a enfrentar o tema,qual seja, o vazio de pensamento.

O impulso imediato derivou do fato de eu ter assistido ao julgamento de Eichmann em Jerusalém. Em meu relato, mencionei a "banalidade do mal"(...)O que me deixou aturdida foi que a conspícua superficialidade do agente tornava impossível retraçar o mal incontestável de seu atos, em suas raízes ou motivos, em quaisquer níveis mais profundos. Os atos eram monstruosos, mas o agente - ao menos aquele que estava agora em julgamento - era bastante comum, banal, e não demoníaco ou monstruoso. (...) não era estupidez mas irreflexão. Clichês, frases feitas, adesão a códigos de expressão e conduta convencionais e padronizados têm a função socialmente reconhecida de nos proteger da realidade, ou seja, da exigência de atenção do pensamento feita por todos os fatos $e$ acontecimentos em virtude de sua mera existência.Foi essa ausência de pensamento - uma experiência tão comum em nossa vida cotidiana, em que dificilmente temos $e$ muito menos desejo de parar e 
pensar - que despertou meu interesse. (ARENDT,2002, p.5-6)

A perplexidade de Arendt mesmo ocorrendo em outro contexto, pode oferecer um aparato provocativo bastante pertinente para a presença da filosofia na sala de aula. Para ela "vazio de pensamento" é algo tão comum em nossa vida cotidiana, que abre espaço para o paradoxo referente à hipótese: se todos pensam por que há um "vazio de pensamento"? A afirmação é tão radical que aponta para uma adesão a um "pensamento pronto" que em certa medida nos "protege" da realidade (do mundo). Então a pertinência da autora para um debate sobre a filosofia em sala de aula, se justifica na medida em que ela rearticula o pensar como uma atividade de resistência a uma "alienação do mundo" ou uma perda da realidade. Nas palavras da autora seria afirmar que tal atividade é politicamente importante, porém em nossa leitura ela é educacionalmente necessária.

\section{A especifidade do pensar filosófico $e$ a filosofia como disciplina}

O lugar que tem sido defendido para a filosofia no currículo do Ensino Médio brasileiro é o de uma disciplina que tenha caráter interdisciplinar. Antes da Lei 11.684/08, que alterou o artigo 36 da Lei 9.394/96 a filosofia era exigida como conteúdo transversal, de modo que a sua presença na condição formal de disciplina era facultativa. Ou seja, o seu lugar curricular era e ainda é sustentado como um ponto interdisciplinar, um elo de conexão entre os diversos saberes.

A compreensão da Filosofia como disciplina reforça, sem paradoxo, sua vocação transdisciplinar, tendo contato natural com toda ciência que envolva descoberta ou exercite demonstrações, solicitando boa lógica ou reflexão epistemológica. Da mesma forma, pela própria valorização do texto filosófico, da palavra e do conceito, verifica-se a possibilidade de estabelecer proveitoso intercâmbio com a área de linguagens.(MEC, 2008, p.18)

Entretanto, o que se coloca é a necessária articulação da identidade da filosofia no intuito de que a inter ou transdisciplinaridade não sejam uma justificativa que obscureça a identidade da filosofia e sua especificidade. Analisar a sua condição de disciplina considerando os pressupostos por trás desse conceito pedagógico é condição necessária para a sua real inserção e contribuição efetiva na esfera educacional.

Assim, sem negar a possibilidade e a rica experiência que a inter e/ou a transdisciplinaridade podem trazer, o que aqui julgamos necessário é refletir sobre alguns elementos que caracterizam a especificidade da filosofia no intuito de garantir o seu lugar disciplinar sem abrir mão de sua própria identidade.

\section{A especificidade filosófica do parar para pensar}

Hannah Arendt ao percorrer a atividade do pensar inicia por confrontar essa atividade dizendo que 
nunca se está mais ativo quando se pensa, de modo que a contemplação exercida pelo pensamento, ao contrário de ser uma mera passividade é uma extrema atividade.

(...) encerrei esse estudo da vida ativa com uma curiosa sentença que Cicero atribuiu a Catão.Este costumava dizer que "nunca um homem está mais ativo do que quando nada faz, nunca está menos só do que quando a sós consigo mesmo (...) Supondo que Catão esteja certo, as questões que se apresentam são óbvias: o que estamos "fazendo" quando nada fazemos a não ser pensar?Onde estamos quando, sempre rodeados por outros homens, não estamos com ninguém, mas apenas em nossa própria companhia?(ARENDT,2002,p.8)

O que se apresenta é que o pensar na condição de atividade $e$ atividade qualificada é por vezes um elemento muito ausente, e se pontuarmos com Deleuze vermos que a filosofia é uma produção(atividade) de conceitos, ou um pensar por conceitos. Assim, é possível percorremos a reflexão de Arendt sugerindo que a atividade que supostamente se constitui como um vazio ou ausência denunciada pela autora é o fato de que não pensamos porque assimilamos conceitos, e com isso não os produzimos, não desconfiamos deles tal como Eichmann.

O filósofo é o amigo do conceito, ele é conceito em potência. Quer dizer que a filosofia não é uma simples arte de formar, de inventar ou de fabricar conceitos, pois os conceitos não são necessariamente formas, achados ou produtos. A filosofia, mais rigorosamente, é a disciplina que consiste em criar conceitos.[...] Os conceitos não nos esperam inteiramente feitos, como corpos celestes. Não há céu para os conceitos. Eles devem ser inventados, fabricados ou antes criados, $e$ não seriam nada sem a assinatura daqueles que os criam. Nietzsche determinou a tarefa da filosofia quando escreveu: " os filósofos não devem mais contentar-se em aceitar os conceitos que lhe são dados, para somente limpá-los e fazê-los reluzir, mas é necessário que eles comecem por fabricá-los, criá-los, afirmá-los, persuadindo os homens a utilizá-los. Até o presente momento, tudo somado, cada um tinha confiança em seus conceitos, como num dote miraculoso vindo de algum mundo igualmente miraculoso", mas é necessário substituir a confiança pela desconfiança, e é dos conceitos que o filósofo deve desconfiar mais, desde que ele mesmo não os criou. (DELEUZE,1992. p.13-14)

Nestes termos, continuando o Diálogo Arendt/Deleuze, para ele o processo filosófico de conceituar não se situa num mundo abstrato ou em meras articulações de dedução lógica de proposições, mas o dinamismo do pensar, de suas várias conexões $e$ relações infinitas se dá num constante contato entre conceitos que se renovam, em virtude de problemas e da constituição de novos planos nos quais os problemas inserem os novos conceitos.

Os planos, é necessário fazê-los, e os problemas, colocá-los como é necessário criar os conceitos. O filó-

Número 21: novembro/2013 - abril/2014 
sofo faz o que pode, mas tem muito a fazer para saber se é o melhor, ou mesmo se interessar por esta questão. Certamente, os novos conceitos devem estar em relação com problemas que são os nossos, com nossa história e sobretudo com nossos devires (DELEUZE, 1992, p.40).

De modo que no entender de Arendt é no pensamento, pela desconfiança que ele desperta, que nos atemos para uma conexão com o mundo. Então, diversamente de ser uma distração o pensar é, na perspectiva arendtiana $e$ aqui em sintonia com Deleuze, uma atividade necessária para uma conexão com o mundo, $e$ no caso aqui sustentado o mundo das aparências. Então falamos de um exercício conceitual que se anima pela capacidade de problematizar para atualizar a atividade de conceituar.

Assim, o diálogo que caracteriza a filosofia como há pouco sugerimos só se faz nesse embate rigoroso, problemático e conceitual. O "fazer" da filosofia, enquanto disciplina, é um percorrer conceitos desconfiando $e$ debatendo com eles. Alcançar esse patamar configura a dificuldade a ser enfrentada contra a banalidade, seja ela a banalidade de problematizar; seja a banalidade de uma visão equivocada de uma aula de meras opiniões infundadas ou a banalidade da pura erudição conceitual. Encontrar o que é para Arendt o centro de sua pergunta é também um desafio para a filosofia como disciplina, ou seja, pensar uma atividade radical tão ativa quando a ação e não menos só quanto a contemplação, por isso é fundamental saber ou encontra o que nos faz pensar.

O que se sugere aqui é a saída de um lugar comum que muito nos conduz a clichês filosóficos.O que se propõe é que considerando a especificidade da filosofia, fazer pensar ou criar condições para parar e pensar seja um horizonte delimitador da identidade da filosofia como disciplina, sem correr o risco de desnaturar o que a constitui.

Hannah Arendt (1997) ao tratar do animal laborans e da ação se viu diante de algo que poderia superar o pensar em nível de atividade, a ação e o labor. Entretanto ela mostra que, na modernidade, e na sociedade a condição de animal laborans, suplanta a ação $e$ até o pensar, num frenético movimento de consumo, para pensar fica cada vez mais escasso.

Na medida em que o entretenimento e o consumo tomam conta do ócio do animal laborans pouco é o tempo para parar para pensar.Consome-se e destrói-se pouco a pouco a possibilidade da durabilidade.Nada é durável, tudo é consumível e diluível no fluxo da necessidade. Um mundo de necessidades, uma prisão para o ócio.

Essa é uma constatação fundamental que traz uma série de questões relativas ao ensino de filosofia e seu lugar no currículo e na sala de aula. $\mathrm{O}$ fluxo das disciplinas na escola média pautado num consumo de conteúdos, num âmbito cada vez mais frenético 
de conteúdos a serem assimilados, devorados é a necessidade acadêmica do animal laborans.

O que Arendt aponta na vida do espírito são as peculiaridades do pensar e é um pensar que é próprio da filosofia. Se com Deleuze (1992) podemos falar que não é monopólio da filosofia ensinar a pensar ou refletir porque todos de algum modo pensam , é próprio da filosofia um modo peculiar e especifico de pensar. Um modo que segundo Arendt é tão ativo quando a ação.

Caso sigamos a proposição de Arendt, será possível constatar que o vazio de pensamento é mesmo algo tão comum na vida moderna, que Eichmann será apenas um exemplo.

\section{O pensar como elemento caracteriza- dor da filosofia}

Na medida que Arendt percorre a tradição filosófica no embate entre ser e aparecer, ela mostra que o que se pretende chamar de pensar típico da filosofia, não se encontra na banalidade das opiniões, mas no rigor da construção conceitual. Com Deleuze, ela caminha numa tentativa de mostrar que conceituar é uma forma de pensar no intuito de construir um sentido e um significado, e muitas vezes tal como um espectador, olhar a distância a trama da vida para tentar compreendê-la.

Na medida em que as ciências criam conceitos para nomear, definir, a filosofia articula conceitos com o intuito de compreender. Na realidade a objetividade do mundo é opaca sem o expectador que olha, admira, encanta, espanta e experimenta a perplexidade.

A filosofia não é um conjunto de conteúdos básicos e fundamentais para a vida como aprender a fazer contas, ler ou escrever. Ela é um adentrar-se em si mesmo, tal como Sócrates, e nesse sentido adentrar-se é mergulhar num mundo de significados e sentidos, e não na opacidade da objetividade das coisas.

A filosofa é disciplina avessa ao processo de devoração de conteúdo, ela é processo degustativo de conceito, talvez uma ruminância conceitual. Impor à filosofia a pressa quantitativa do conteúdo é submetê-la a ser aquilo que não é: mais uma disciplina no laborioso complexo processo de devoração, que não para pra pensar.

Ainda no texto "A vida do Espírito" Arendt, após percorrer posições de diversos "pensadores profissionais", recupera a figura de Sócrates como um paradigma do parar para pensar, da ruminância conceitual, que nada produz, mas que a tudo rumina e desconstrói. É um pensar que não se preocupa em produzir, em oferecer um conceito, mas mesmo pensando por conceitos, paradoxalmente não chega a produzir conceitos.E para Arendt, a grande questão sobre o que nos faz pensar passa pela saída da banalidade para ser capaz de experimentar a densidade da perplexidade.

Não é que eu deixe os outros perplexos, já conhecendo as respostas. A verdade é que eu lhes transmito a minha própria perplexidade. Esta é, evidentemente, a expressão con- 
cisa do único modo como o pensamento pode ser ensinado (ARENDT, 2002, p.129).

A perplexidade é o ponto fundamental para Arendt, por ela desvela-se como o caráter devorador do labor na vida moderna nos joga num fluxo de atividade que não comporta a não temporalidade do pensamento.Na medida em que para Arendt a perplexidade é um fator que nos faz pensar no sentido filosófico da expressão, a densa banalidade é elemento gerador do "vazio de pensamento". Assim, se a filosofia for um conjunto de conceitos a serem devorados ela não nos fará pensar. $\mathrm{O}$ percurso da história da filosofia precisa ser um momento de experiência com a perplexidade e de ruminância conceitual, pois na linguagem de Arendt é ela que nos protege das "fantasias" do real.

$\mathrm{Na}$ ótica socrática sustentada por Arendt (2002, p.130) a atividade do filósofo seria "ferroar" o interlocutor para despertá-lo para o pensamento e para a investigação, de modo que uma vida sem pensamento ou sem a investigação não valeria a pena ser vivida. Ainda para Arendt, (2002, p.130) Sócrates, o paradigma do filósofo, purgava as pessoas de suas opiniões, e que no caso eram os préconceitos não examinados e que, certamente, impediam as pessoas de pensar. Para a autora significava livrálos de um mal sem necessariamente torná-los bons ensinando-lhes a verdade.O fato é que Sócrates mesmo se defendendo das acusações de cor- romper a juventude em momento algum afirma torná-los melhores (ARENDT,2002,p.130-131) .

Assim, se pensamos a identidade do docente como aquele que toca os alunos com a perplexidade, a filosofia também como disciplina precisa ver-se no currículo do Ensino Médio como provocadora da perplexidade. Arendt se apropria da metáfora do vendo usada por Sócrates para caracterizar a atividade de pensar. Os ventos eles mesmos invisíveis, mas o que eles fazem mostra-se a nós e, de certa maneira, sentimos quando eles se aproximam. (ARENDT, 2002, p.131).

No vento do pensamento mora o risco da filosofia, ou o risco da perplexidade, ele tanto desperta quanto varre aquilo que está estático, dá movimento, e muitas vezes, tal como o vendo, é um movimento que agita as estruturas do que está de pé. Ele derruba paredes e desvela o que há por trás delas, ele retira do lugar o que estava fixamente estabelecido. A perplexidade neste caso é sentir-se varrido, mexido, desalojado.

A consequência é que o pensamento tem inevitavelmente um efeito destrutivo e corrosivo sobre todos os critérios estabelecidos, valores, padrões para o bem e para o mal, em suma, sobre todos os costumes $e$ regras de conduta com que lidamos em moral e ética. Estes pensamentos congelados, Sócrates parece dizer, ocorrem tão facilmente que até dormindo podemos fazer uso deles; mas o vento do pensamento que agora provoquei sacudiu você do seu sono e deixou-o totalmente disperto e vivo, você verá que pode dispor apenas de per-

Número 21: novembro/2013 - abril/2014 
plexidades, e o melhor que se pode fazer com elas é partilhar-las com os outros. (ARENDT, 2002, p.131132).

$\mathrm{Na}$ radicalidade e no fluxo do vento o pensamento é perigoso, pois ele pode desconstruir; as regras prontas não resistem ao vento do pensamento. Frente a isso, é possível que na perplexidade do pensamento $\mathrm{o}$ oposto dos conceitos seja gerado, nessa circunstância o niilismo é mais que uma possibilidade é um risco real( ARENDT, 2002, p133). Não há pensamentos perigosos; o próprio pensamento é perigoso (ARENDT, 2002, p.132).

De modo que falar da filosofia $e$ de sua identidade de algum modo implica em considerar que ela não aperfeiçoa ninguém, mas apenas desperta, e segundo a visão que Arendt (2002) tem sobre Sócrates isso parece um grande bem para a cidade. A ausência de pensamento está na presença de códigos prontos, sólidos e aceitos. O pensar é uma desestabilização. Para a autora o mal banal estaria vinculado a ausência de pensamento, ou seja, a incapacidade para sentir a perplexidade.

Frente a tudo isso a identidade da disciplina dita a identidade do docente.Como a disciplina não é uma mera conversação despretenciosa, nem tampouco um conceituar ao modo da ciência moderna, é evidente que o docente se constitui no seio da disciplina, na experiência rigorosa $e$ sistemática com essa atividade desconstrutora e geradora de perplexida-
de.No caso brasileiro e da pesquisa que estamos realizando é fato que há um número muito grande de docentes de filosofia que não são licenciados em filosofia, são professores de áreas diversas, e que adentram a sala de aula para "ensinar" filosofia. Para o docente licenciado a própria ensinabilidade da filosofia é um problema filosófico a ser enfrentado. Por isso, falar da identidade do docente de filosofia implica em abordar o modo como o docente transmite a perplexidade, já que tal como analisamos aqui, a perplexidade é o modo de se "ensinar" a pensar.

Assim, percorrer a experiência de perplexidade dos filósofos desenvolvida pela história da filosofia é uma das vias possíveis de se problematizar a atualidade dos conceitos $e$ de descontruir a estabilidade conceitual que nos acomoda e nos paraliza para o pensar.

\section{O olhar dos alunos sobre o lugar cur- ricular da filosofia}

Em nosso primeiro contato com a Filosofia no Ensino Médio, nos deparamos com um grande obstáculo em entendê-la, uma vez que estamos impregnados de preconceitos e de modalizações a respeito de tal disciplina. Ao tentarmos conceituá-la, já nos envolvemos com um dos grandes problemas da Filosofia: encontrar um conceito que abranja todas as suas características.

Com o decorrer das aulas, nós fomos quebrando os preconceitos e, 
com a ajuda do professor, sendo levados a um mundo de questionamentos, onde a busca do saber foi se tornando cada vez mais constante. É importante destacar que uma aula de Filosofia se torna mais interessante para o aluno à medida em que nela é inserida a atividade do questionar.

A pergunta "De que maneira vemos a Filosofia como uma disciplina do Ensino Médio?" foi o ponto de partida para que pudéssemos avaliar as leituras que já fizemos para o nosso projeto, assim como analisar nossa própria vivência com a Filosofia em sala de aula.

A Filosofia que estudamos, atualmente, percorreu um longo processo de inserção e reinserção nos currículos escolares e a sua presença como disciplina esteve sempre ligada ao contexto sócio-histórico do Brasil. O primeiro momento em que ela foi acrescentada às grades curriculares correspondeu ao período da Independência do Brasil.

Porém, com a ditadura militar, ela foi considerada uma disciplina que poderia contrariar o interesse dos militares, pois estes não desejavam que a sociedade fosse formada por indivíduos que questionassem o regime político. Com o fim deste período e a volta da democracia, a Filosofia reaparece no contexto do ensino médio como que para desenvolver nossa capacidade de problematização e reflexão.

Daí surgiram vários problemas como: o pequeno número de licenciados em Filosofia versus a alta de- manda das escolas brasileiras, a expectativa dos alunos, as metodologias errôneas usadas em sala de aula $e$ a disseminação das ideologias capitalistas que nos influencia a buscar uma utilidade prática em tudo ao nosso redor. Estes problemas serão mais detalhados daqui para frente.

Primeiramente, nós observamos que há uma grande deficiência no número de professores de Filosofia e isso tenta ser contornado com programas governamentais como o "Programa Emergencial de Segunda Licenciatura". Porém essas medidas só pioram o nível da educação, pois tentam capacitar professores de áreas diversas a ensinar a Filosofia e esta disciplina possui uma especificidade que não será abordada em sua totalidade por professores graduados em outra matéria.

Outra questão importante que analisamos é a atitude dos alunos do ensino médio frente à inserção da Filosofia no currículo escolar. Percebemos que há uma crescente falta de credibilidade acerca da instituição escola, os jovens já não se apresentam tão responsáveis como antigamente e o compromisso com a própria educação já não é mais valorizado. Isso acontece porque, por muitas vezes, os conteúdos tradicionais são passados de modo enciclopédico, tornando o aluno um ser passivo em sala de aula e favorecendo a memorização. Acreditamos que a Filosofia rompe com essa ideia que se tem do ensino, pois exige uma postura ativa de cada aluno, através de argumentos 
e problematizações. A capacidade do re-perguntar e a adoção de uma postura crítica é essencial para a vida. É esse descontentamento que proporciona a evolução de todos os conhecimentos, tanto da área da filosofia quanto das outras áreas científicas.

Outro problema são as metodologias adotadas. Os professores, geralmente, se utilizam de duas correntes de ensino de Filosofia: a históricoteórica e a temática problemática. A primeira, histórico-teórica, acaba resultando em um conteúdo meramente enciclopédico e o aluno vê-se diante de uma abordagem conceitual já pronta e que não exige questionamentos. Já o eixo temáticoproblemático pode levar a uma fuga do foco da análise filosófica por se preocupar com a problematização $e$ deixar a desejar o arcabouço teórico. Assim, o melhor processo de ensinoaprendizagem da Filosofia é uma terceira via didática, que é adotada por nosso professor na escola, a qual abarca a história da filosofia, a problematização das teorias e o estímulo à argumentação dos alunos.

E por fim, outro problema é o das ideologias capitalistas disseminadas em nossa sociedade, pois a escola torna-se um meio em que se pode incutir nos alunos essas ideias homogenizadoras de forma implícita e sutil. Assim, cabe ao professor driblar a coerção político-social das instituições capitalistas e trabalhar a Filosofia de forma a gerar indivíduos mais autônomos, críticos e transformadores da realidade.
Deste modo, acreditamos que cada professor de Filosofia, não só deve ensinar a Filosofia (história, conceitos e teorias) como também ensinar a filosofar (através da argumentação, problematização e reconceitualização) e a perceber sua importância como um conteúdo interdisciplinar no contexto das disciplinas do Ensino Médio.

Após compreendermos os vários proveitos proporcionados pela filosofia ao aluno do Ensino Médio, contrariamos o senso comum que acredita que a Filosofia não tem uma utilidade concreta para o aluno no Ensino Médio. Uma vez que o ensinar a Filosofia também é o ensinar a filosofar e este filosofar não significa divagar a respeito de idéias sem sentido. O filosofar é o meio em que o ser, a partir do pensamento, passa a questionar e colocar-se contrario a tudo aquilo que se diz tão simples e tão obvio, ou discordar de algo que outro prega ou ensina. Assim a filosofia no Ensino Médio, para nós, alunos, não se restringe à memorização $e$ ao enciclopedismo como, de modo geral, é visto pelo senso comum; ela é como um divisor de águas entre a alienação $e$ o mundo do saber consciente do conhecer atuante.

\section{Conlusão}

O que se propôs a título de especulação neste texto, percorrendo a expeculação do professor $e$ a perspectiva dos alunos foi o enfrentamento referente ao fato de que a filosofia ao ser institucionalizada como disciplina 
obrigatória no ensino médio precisa ver com atenção a sua condição disciplinar, sua interação com as outras disciplinas e a própria exigência educacional que lhe é feita, tendo por horizonte a manutenção de sua própria identidade.

A filosofia precisa ser filosofia, $e$ não um nome para conteúdos diversos, por isso o que se quis demonstrar foi que é necessário, na articulação curricular, saber em que consiste a filosofia e a partir disso estabelecer as relações possíveis com as outras disciplinas no intuito de uma inter ou transdisciplinaridade. Afinal, considerando o dia-dia da escola e da sala de aula é necessário ver com cautela as expectativas que são depositadas na filosofia, de modo a evitar uma visão que considera a filosofia uma disciplina capaz de fazer tudo, deixando de lado aquilo que the é peculiar, o parar para pensar.

Outro ponto considerável é o fato de que para a própria metodologia de ensino é importante que o professor filósofo entenda-se com a didática e com a reflexão educacional, pois a nossa perplexidade precisa entrar em contato com os alunos, mas sem renunciar a radicalidade e a identidade da filosofia. Nesta perspectiva é possível ver nela uma disciplina que contribui com as outras e com a totalidade do processo de ensino desenvolvido na escola à medida que realiza o que a qualifica e identifica.

Caso tomemos como válida a proposição arendtiana do parar para pensar, trabalhar com a disciplina via história da filosofia, via problemas ou temas será apenas um dos caminhos possíveis, a atitude com a qual enfrentamos esses "métodos" é que precisa ser filosófica, precisa nos possibilitar um parar para pensar.

Nesse sentido ser professor filósofo, falando da identidade do docente, implica em ver-se envolvido pela perplexidade própria da filosofia. Não há como falar da identidade do docente sem percorrer a identidade da disciplina. De modo que para assumir a docência de filosofia é condição necessária que o docente seja de fato professor filósofo, ou seja, alguém licenciado em filosofia, pois se a identidade do docente se constitui na experiência intelectual com a filosofia, com suas perplexidades, com seus riscos, tal fato se estabelece no processo formativo do PROFESSOR DE FILOSOFIA.

Assim, o debate curricular referente à presença da filosofia na escola implica em sustentar o lugar da filosofia como disciplina, porém de delimitar a sua identidade e com isso a exigência de "competências" específicas para atuar com essa disciplina em sala de aula, sob o risco de a termos como presença institucional mas não de fato, pela ausência do Professor filósofo. O risco de tudo isso é que uma presença institucional junto a uma ausência de fato pode ser uma oportunização para desvalorização da disciplina que perde o momento oportuno para sua real consolidação no processo educacional da Ensino Médio brasileiro.

Número 21: novembro/2013 - abril/2014 


\section{REFERÊNCIAS}

ARENDT, Hannah. A condição Humana. Trad. Roberto Raposo. Rio de Janeiro: Forense Universitária, 1997.

A vida do espírito. Trad. Antônio Abranches. Rio de Janeiro: Relume Dumará, 2002.

Entre o passado e o futuro. Trad. Mauro W. Barbosa. São Paulo: Perspectiva, 2003.

BRASIL, Lei 9394 de 20 de dezembro de 1996. Disponível em<: http://www.planalto.gov.br/ccivil 03/Leis/L9394.htm > Acesso em 20/04/2011.

CERLETTI,Alejandro.O ensino de filosofia como um problema filosófico. Belo Horizonte: Autêntica, 2009.

DELEUZE,Gilles;GUATTARI,Félix. O que é filosofia? Trad. Bento Prado Jr. e Alberto Alonso Muñoz. Rio de Janeiro: 34.1992.

GATTI, Bernadete Angelina (coord); BARRETO, Elba Siqueira de. Professores do Brasil: impasses e desafios. Brasília: Unesco, 2009, p.78.

GELAMO, Rodrigo Pelloso. O ensino da filosofia no limiar da contemporaneidade: o que faz o filósofo quando seu ofício é ser professor de filosofia? São Paulo: Cultura Acadêmica, 2009. Disponível em< http://www.culturaacademica.com.br/downloads/\%7BDE44A0D1-1710-4F9BB0F8-347122201111\%7D Ensino da filosofia_limiar da contempNOVA\%20P4.pdf $>$ Acesso em :01/05/2011

KOHAN, Walter. (org.) Ensino de filosofia - perspectivas. Belo Horizonte: Autêntica, 2005.

MEC. Secretaria de Educação Básica. Orientações Curriculares para o ensino médio.Vol.3.Brasília:MEC, 2008. Disponível em < http://portal.mec.gov.br/seb/arquivos/pdf/book_volume_03_internet.pdf $>$ Acesso em: 20/04/2011.

PAPADOPOULOS, George S. Aprender para o Século XXI. In: DELORS, Jacques (org). A educação para o século XXI- questões e perspectivas. Trad. Fátima Murad. Porto Alegre: Artmed, 2005.

PEREIRA, Geraldo Adriano Emery et al. A identidade da disciplina Filosofia e do docente no currículo do Ensino Médio. Revista Sul-Americana de Filosofia e Educação. Número 21: nov/2013-abr/2014, p. 3-16. 
SILVA, Tomaz Tadeu da. O currículo como fetiche - a poética e a política do texto curricular. Belo Horizonte: Autêntica,2010.

SCHOPENHAUER, Arthur. Sobre a Filosofia e seu método. Trad. Flamarion Caldeira Ramos. São Paulo: Hedra,2010, p. 29-49

Recebido em 28/04/2013

Aprovado em 01/08/2013 